\section{Comprendiendo el espacio desde otras escalas: la geografía del habitar como geo-grafía y geo-política cotidiana*}

\section{Understanding space from other scales: lived geographies as everyday geography and geopolitics}

\author{
ANDRÉS NúÑEZ \\ Matthew C. Benwell ${ }^{\star * \star}$
}

Los autores agradecen el apoyo de los proyectos Fondecyt $\mathrm{N}^{\circ}$ 1170643 (CONICYT, CHILE) e INTERNATIONAL PARTNERSHIP FUND, Newcastle University, UK.

** Instituto de Geografía, Pontificia Universidad Católica de Chile.

*** School of Geography, Newcastle University, UK
Tradicionalmente, los estudios de geografía han transitado por escalas y puntos de vista que más se asocian a lo imperial, lo nacional o lo global, así como a representaciones de elites y ámbitos del poder y en menor medida a escalas que podríamos vincular a la experiencia del habitar o narrativas y prácticas donde lo cotidiano sea lo central. En este contexto, sería posible hablar de una geografía mayor para denotar el nexo tradicional existente entre geografía y poder, en tanto, en general, ella -es decir, la producción de un tipo de saber geográfico- ha servido como estrategia para controlar e incorporar territorios a los imperios o las naciones. Desde hace ya algunas décadas, sin embargo, especialmente en los marcos de los Estudios Culturales, del Ilamado giro cultural y del propio giro espacial en la geografía, es posible abrir los estudios geográficos a nuevos puntos de vista y cruces temáticos. Así, por ejemplo, el espacio lejos de ser únicamente material derivará en espacio existencial, y desde una fuerte base fenomenológica, implicará comprenderlo desde sus procesos de significación social o, como expone Joan Nogué (2015:142), "desde las emociones y desde los procesos inmateriales e intangibles que convierten a cada lugar en algo único e intransferible".

En esa línea, en este dossier buscamos acercarnos a aquellas problemáticas de la geografía donde precisamente lo cotidiano y el habitar sean el elemento articulador. Más allá, planteamos que desde lo cotidiano surgen discursos, experiencias y prácticas que lejos de ser pasivas o neutras están cargadas de lógicas que también constituyen identidades geopolíticas. Así, detrás de una suerte de uniformidad geográfica, sea nacional o global, 
devienen sentidos íntimos o menores que también intervienen tanto en la producción de una memoria de tipo local como en una de alcance nacional. A esta escala de análisis la hemos llamado geografías menores, en contraposición a la geografía mayor ya indicada, para denotar la necesidad de des-centrar la mirada monopolizada por imágenes y métodos geográficos que, como expresamos, más se han asociado a una geopolítica estatal o imperial que a un devenir cotidiano. Aquello reflejaría, como han apuntado Massey $(2005,2012)$ y Deleuze (2002), la multiplicidad de historias territoriales que desde diversas escalas y relaciones se desenvuelven en sus propias trayectorias espacio-temporales.

En este contexto, este dossier propone replantear la comprensión geográfica de lo geopolítico ya no únicamente en el ámbito de la organización de escala global o nacional sino también desde los espacios domésticos, diarios y/o del habitar. Así, la "geopolítica de lo cotidiano" es algo que ocurre afuera del ámbito académico, de los discursos geopolíticos/diplomáticos, es decir, de los espacios tradicionales de la investigación de la geopolítica. La clave en esta renovada perspectiva es preguntarse cómo afecta la vida cotidiana de los ciudadanos al poder y cómo ellos pueden afectar e influir los procesos de la geopolítica. Ellos, los ciudadanos, no son a-políticos, sino que son agentes potencialmente activos (Hörschelmann and El Refaie 2014; Koopman 2011). Desde esta perspectiva, una geografía visitada desde lo cotidiano, del espacio del habitar, puede ser una respuesta de resistencia -es decir, como espacio de resistencia- a lógicas de escala normativas amplias que poco o nada dialogan con el diario vivir.
Así, el concepto geografía cotidiana también ocupa en la actualidad un lugar importante en las ciencias sociales al amparo de la geografía cultural y la geografía social (Lindón y Hierneaux 2010). El intento de entender las prácticas, el cotidiano y las cosas ordinarias de la vida tiene una historia en la filosofía. Tal vez lo expuesto por Michel de Certeau (2010: 7) resuma la perspectiva: "El hombre común a través de sus prácticas cotidianas se reapropia de un espacio organizado por los técnicos de la producción sociocultural".

El punto es crucial, por ejemplo, para comprender la producción del ciudadano nacional, ya que esas prácticas, ese ordinario vivir, lejos de ser insignificante se torna vital en la organización y/o resistencia de las espacialidades locales. En efecto, como ha planteado el propio De Certeau (2010), no todo estaría disciplinado y controlado ya que, en las trayectorias ordinarias y cotidianas, la imagen de los fabricantes de lo nacional/global es mediada e intervenida por las prácticas y por geografías menores que se desenvuelven forjando horizontes propios y únicos. Tal vez por lo mismo, estas vivencias banales, simples, ordinarias, ancladas en una memoria móvil, cofabrican los sentidos espaciales "desde abajo", ya sea para reafirmar las proyecciones de la escala nacional/global o para des-enmarcarse de esas miradas surgidas desde los centros del poder.

De este modo, como veremos a continuación, el presente trabajo de compilación ha buscado indagar, en lo sustancial, en torno a ese mundo cotidiano, un mundo que también implica geopolítica. En efecto, como podráser observado en los trabajos, hay prácticas, espacios públicos y memorias que supondrán un reconocimiento estrecho con el orden discursivo emanado 
desde los centros políticos. Y, por otra parte, se observan lazos de pertenencia a territorios construidos y proyectados desde innumerables acciones que suponen una superación de lo global, de lo nacional.

Algunas preguntas que surgen en este contexto de este dossier son: ¿Cómo se puede conectar las escalas/espacios/agentes geopolíticas en la investigación? ¿Cómo se puede investigar la geopolítica del estado y la geopolítica de la cotidianeidad? ¿La investigación de la geopolítica de la cotidianeidad puede ofrecer una geopolítica alternativa (Koopman 2011)? ¿Cómo se puede reconocer y facilitar la agencia de los ciudadanos en cuanto de la geopolítica? ¿Si el espacio es un producto político, es posible pensar en un espacio que surja desde una política que considere lo cotidiano como sujeto social protagonista (desde las prácticas y las vivencias de la ciudadanía)? ¿Es posible proyectar el espacio cotidiano como un articulador de espacios de resistencia?

En este marco, el artículo "Geografías menores, geografías cotidianas: la construcción del ciudadano nacional en Chile Chico, Región de Aysén" de Andrés Núñez, Matthew Benwell, Enrique Aliste y Javiera Muñoz busca precisamente indagar en torno a esas preguntas e instala la construcción del ciudadano nacional en la localidad de Chile Chico (Aysén-Chile) como elemento central del análisis. Desde este soporte se plantea que el ciudadano nacional no solo se produce desde el centro político sino, especialmente, desde su devenir cotidiano, desde su quehacer silencioso y menor que implican sus prácticas, donde ellos co-fabrican sentidos nacionales desde los simbolismos y materialidades presentes en sus respectivos territorios. De este modo, observan como la educación, el espacio doméstico (hogar) y público, las banderas, los murales y las diversas ceremonias se despliegan como estrategias locales que dialogan con lo nacional, tornándose herramientas desde donde se afianza precisamente el ciudadano nacional. Así, es relevante la lógica cultural de autogobierno que se desenvuelve en esas prácticas. Cabe mencionar, como resaltan los autores, que Chile Chico se encuentra a solo 14 kilómetros de Los Antiguos (Santa Cruz, Argentina) y que esa cercanía también refleja una memoria común que rebasa lo propiamente nacional. Por lo mismo, subrayan que los ciudadanos, desde sus geografías menores y cotidianas, se tornan tanto agentes geopolíticos que producen y rehacen el sentido comunitario y de pertenencia a la nación como, a su vez, en agentes de una memoria que pone en valor un devenir que les pertenecía incluso antes que llegará la nación y sus límites.

En la misma región de Aysén (Chile), el trabajo de Sofía Pérez, titulado "Geopolíticas del cotidiano y campos de hielo patagónicos. La construcción del habitar en una región fronteriza", propone replantear los cuestionamientos en torno a los estudios de frontera, utilizando la perspectiva de la geopolítica crítica y el cambio de paradigma espacial planteado por la corriente feminista de la geopolítica cotidiana. De esta forma, es posible corporalizar el espacio, a través de la visibilización de las dinámicas cotidianas de los habitantes que construyen su habitar a partir de las políticas nacionales, en una zona donde persiste una tensión diplomática histórica: el caso de la frontera chileno-argentina sobre los Campos de Hielo Sur en la Patagonia. Por medio de esta investigación, la autora intenta avanzar en la reflexión geográfica en el campo de los estudios de frontera patagónica, interrogando 
los efectos de las divergencias entre las políticas de integración y las de seguridad de los Estados y el control del territorio, sobre las experiencias de un cotidiano que se dinamiza gracias al turismo transfronterizo, entre las ciudades de El Chaltén en la provincia de Santa Cruz (Argentina), y Villa O'Higgins, en la región de Aysén (Chile).

En el artículo de Alba Griffin, titulado "Negociando el derecho a la ciudad: grafiti en Bogotá", se propone considerar las voces de los habitantes en relación a sus prácticas creativas cotidianas y perspectivas sobre lo que significa vivir en la ciudad y expresarse políticamente y estéticamente en esta. La intención del artículo es demostrar como un análisis alineado con la idea de una geopolítica de lo cotidiano expone las prácticas políticas y cotidianas de los habitantes urbanos, apuntando a visibilizar la complejidad de las negociaciones e interacciones entre el estado y los ciudadanos en la búsqueda del derecho a la ciudad.

Siguiendo el enfoque lefebvriano, el derecho a la ciudad se presenta como una denuncia de las realidades de exclusión y alienación en la sociedad urbana y un llamado a la justicia social. Una de las ideas fundamentales es que los que habitan la ciudad - los subalternos, las clases trabajadoras - deben tomar las decisiones para transformar la ciudad y deben participar en la producción de esta. Según Lefebvre, la apropiación del espacio urbano por parte de estos grupos sociales indicaría una ciudad más democrática. El grafiti se presenta de esta forma en Bogotá, Colombia, como una expresión política de participación y apropiación del espacio público a través de la legitimación de la práctica creativa y su transformación estética.
El tema de la normalización aparece de forma relevante a lo largo de todo el artículo, no solo el Estado atenta contra la participación de los grafiteros, es también la clase de elite y otros habitantes que hacen referencia a romper "el buen orden" de la vida urbana y establecen estereotipos (como los "sin respeto" o "vagos"), denotando una jerarquía social que reproduce a su vez una jerarquía estética hegemónica.

A su vez, el artículo "Violencia, espacio y vida cotidiana en la guerra mexicana contra las drogas: un análisis de Tijuana", Héctor Bezares propone un análisis que examina el modo en el que el espacio urbano en la ciudad fronteriza de Tijuana ha sido resignificado como un territorio marcado por la inseguridad y la violencia en el contexto de la estrategia antinarcóticos mexicana. Dicha representación coincide con la expansión urbana y demográfica de la ciudad, enmarcada en un proceso de inserción en la circulación continental de las drogas. La guerra contra las drogas en México, declarada a comienzos del año 2007 por el presidente Felipe Calderón Hinojosa, ha organizado un espacio en el que ejercicio de formas de violencia es constante, afectando a la vida cotidiana de la ciudad, generando de esta forma consecuencias que impiden el libre ejercicio del derecho a la ciudad; su organización, uso y disfrute por parte de los habitantes de Tijuana.

La guerra contra las drogas, a través de la representación y configuración de Tijuana como un espacio inseguro, ha producido las condiciones necesarias para que sus residentes sean vulnerados por la expansión del miedo e incertidumbre, generando auto-encierro y el consecuente abandono de los espacios públicos; sumada también a la proliferación de la violencia que ha acompañado el crecimiento 
demográfico y territorial de la ciudad. En términos de las investigaciones sobre la geopolítica de lo cotidiano, este artículo contribuye así al desarrollo de un debate sobre los aspectos micro-políticos y espaciales de la prohibición de drogas.

Por su parte, en "Lo cotidiano como lugar en disputa en los territorios forestales chilenos, entre dinámicas globales, dispositivos estatales y prácticas populares", Massimiliano Farris y Marcela Salgado reflexionan sobre la importancia del espacio de la cotidianidad en torno a las relaciones de poder involucradas en los territorios forestales de Chile desde una perspectiva transescalar. De esta forma es posible evidenciar la dialéctica existente entre las prácticas hegemónicas territoriales de las grandes empresas territoriales y los mecanismos de resistencia por parte de grupos sociales. Los autores hablan de tres factores determinantes sobre el sector forestal chileno: el rol del Estado, la estructura del holding y su proyección global a través de las exportaciones, la transformación del territorio local y el control sobre la cotidianidad. Fases que develan la marcada connotación ideológica que justifica y sustenta la dimensión productiva.

Con la ley de 1936, se produce un cambio radical en la forma de percibir el bosque; antes se presenta como un recurso natural "aprovechado por el hombre", mientras que hoy se percibe como un recurso "creado por el hombre", generando un proceso de producción y comodificación de la naturaleza. La "creación del bosque" que se entiende como la inserción de nuevos "objetos" (pinos, eucaliptos, plantas de celulosa, etc.), ha transformado directamente el paisaje y la vida cotidiana de estos territorios, reconfigurando, a su vez la estructura social por parte de grupos hegemónicos, afectando y controlando directamente las prácticas cotidianas de grupos subalternos. Es así como las plantaciones se naturalizan como parte del paisaje, son reconocidas como "bosques" y ante los ojos de los habitantes pareciera que siempre han estado ahí, dificultando o imposibilitando la visualización de alternativas de desarrollo para estos territorios.

Se presentan dos casos de estudio. El primero, en la región del Maule, aborda las estrategias de una empresa forestal en producir/resignificar, controlar y dirigir prácticas cotidianas de la población local después de dos acontecimientos disruptivos (terremoto 2010 e incendio 2017). El otro, en la región de Ñuble evidencia la permanencia de prácticas productivas vitivinícolas tradicionales que conforman la cotidianidad territorial del Valle del Itata desde siglos y aparecen "resistentes/resilientes" tanto a la gran industria del vino chilena como a la expansión forestal.

La reflexión final gira en torno al rol que ha desempeñado el Estado otorgando garantías y atribuciones al privado, a la vez que se retrae de sus funciones. Lo anterior, sumado a su carácter poroso, que torna difusa la barrera entre los ámbitos de acción pública y privada, cuestionan la posibilidad actual de configuración de un Estado capaz de asumir funciones contrahegemónicas. 


\section{Bibliografía}

De Certeau, M. (2010). La invención de lo cotidiano. Artes de hacer. México D.F.: Iberoamericana.

Deleuze, G. (2002). Nietzsche y la filosofía. Barcelona, Anagrama Hörschelmann K. and El Refaie E. (2014). "Youth citizenship beyond consensus - examining the role of satire and humour for critical engagements in citizenship education". In Buckingham D., Bragg S. and Keheli M. Eds (2014). Youth cultures in the age of global media Macmillan, Basingstoke.

Koopman, S. (2011). "Alter-geopolitics: Other securities are happening”. Geoforum, 42 (2011), pp. 274-284
Lindón, Alicia y Hiernaux, Daniel (dirs.) (2010): Los giros de la Geografía Humana. Desafíos y horizontes. Barcelona, Anthropos Editorial, Universidad Autónoma Metropolitana.

Massey, D. (2005) For Space, London, Sage.

Massey, D. 2012. "Un sentido global del lugar". Doreen Massey, sentido global del lugar. Albet, A. y Benach, N. (Eds.).Barcelona: Icaria. 112-129.

Nogué, J. (2015). "Introducción”. En Tuan, Yi-Fu, 2015. La geografía romántica. En busca del paisaje sublime. Madrid, Biblioteca Nueva. 